CCRP Working Paper Series

\title{
REFLECTIONS ON RPI-X REGULATION IN OECD COUNTRIES
}

\author{
Jonathan Mirrlees-Black \\ Centre for Competition and Regulatory Policy (CCRP) \\ City University London \\ CCRP Working Paper No 25 \\ (October 2014)
}




\section{Reflections on RPI-X regulation in OECD countries}

Paper presented at the conference The British utility model: beyond competition and incentive regulation, London School of Economics, March 31 2014, held to reflect on the legacy of the 1983 Littlechild report.

Dr Jonathan Mirrlees-Black

Head of Research, RARE Infrastructure, and Visiting Professor, University College London Australia

Contact details: j.mirrlees-black@ucl.ac.uk

\section{Abstract}

The form of regulation initially proposed by the Littlechild (1983) report has not only been implemented in UK regulated industries, but has also become a benchmark approach to regulation worldwide. RPI-X has been widely adopted in different industries in OECD countries both to incentivise efficiency and also to support privatisation, and this paper shows the breadth of countries and industries in which it has been applied. It has also contributed to the development of infrastructure as a separate asset class. It is difficult to overstate the long-term impact of the 1983 paper. However, the precise way in which RPI-X regulation is implemented differs widely. On occasions, a price control process is implemented largely because it is a well-respected benchmark approach, but with less appreciation of the intended objectives. Designers of regulatory frameworks would do well to recall the analysis in the original Littlechild paper which highlighted that regulation is not an end in itself, but a means to an end, and successful applications of the framework respect this.

\section{Keywords}

Infrastructure, utility investment, RAB

\section{Acknowledgements}

This paper has benefitted from suggestions and comments by David Maywald and Ben May of RARE Infrastructure, participants at the conference The British utility regulation model: beyond competition and incentives in March 2014, and an anonymous referee. I would also like to thank Dr Michel Berthélemy of UCL Australia who assisted with the collation of the data. The views expressed here are those of the author, and may not represent those of RARE Infrastructure or UCL Australia. 


\section{Introduction}

It is now over 30 years since the now famous Littlechild (1983) report was published and led to application of the "RPI-X" form of regulation initially in the UK Telecommunications industry, and subsequently in a wide range of other "network" industries including water, electricity, gas, airports, and rail. The approach to regulation has led to the transformation of industries in the UK, and the other papers presented at the conference have demonstrated this as well as highlighting the ways in which the approach has evolved.

This paper considers the impact that RPI-X regulation has had internationally. It has now been adopted in network industries in a wide range of countries, and in this paper we show just how prevalent it is in OECD countries. Many countries have benefitted from the cost savings and other beneficial incentive properties that RPI-X regulation can bring.

In addition, $\mathrm{RPI}-\mathrm{X}$ regulation has also facilitated the transformation of the financing of network industries. The approach is now very familiar to investors, and implementation of it has often accompanied either privatisation or a fundamental industry restructuring, and often both (as in the UK). It has allowed large transfers of assets from public to private investors, and has facilitated investment in new physical assets. This has led in turn to the creation a new asset class, infrastructure, with investors focused on assets many of which are regulated with the RPI-X approach.

Although RPI-X is now very well known as a method of regulation, the term now covers a multitude of regulatory approaches. Any RPI-X regulatory framework involves choices about the mechanics of how price controls are set, and the institutional framework within which they are controlled. The details of these are different for each country and industry and the choices made have important implications for outcomes and success of the framework. Details include: the extent to which changing costs can be passed through to final customers; whether the regulation is used for vertically integrated activities, or just the network components of the business; and whether there is asset protection in the form of a regulatory asset value or similar. For the purposes of this paper, we consider RPI-X regulation to be in place when price controls have this form, and note that there are a wide variety of options for capital protection and institutional arrangements.

We note that in some countries, once the framework is in place the focus of regulation is largely on the implementation of rules, and ensuring compliance with those rules. Working in compliance with the system is seen as the end, rather than achieving the outcomes most in the public interest. RPI-X is now often considered to be considered synonymous with regulatory architecture that includes the use of 
regulatory values, cost of capital determinations and other elements standard in UK price controls. These provide a balance between the needs of different stakeholder groups, with pre-commitment by regulators so that companies have the confidence to make investments (e.g. see Stern (2014)). These approaches have value, in particular where the industry is expected to be regulated indefinitely. They are, however, not necessarily consistent with the original Littlechild (1983) paper, or his subsequent proposals (e.g. see Littlechild (2014)).

This is where a re-reading of the original Littlechild (1983) paper is valuable. RPI-X was seen in that paper as a means to an end, and not an end in itself. RPI-X is a useful tool, it can help achieve certain outcomes, but thought must be given to why it is implemented, in order that it can be done well, or alternatives found if they better meet the needs of the industry. The RPI-X approach with regulatory values and related concepts is often appropriate, but flexibility may be necessary to achieve the right outcome for customers. This is particularly important now. Investment in infrastructure is high up the agenda of many governments. There is wide acceptance that more investment is needed, and it is also seen as a route to supporting an increase in economic growth. Very large investments are needed to support growth. An RPI-X framework can facilitate that investment, but it needs to be well designed.

\section{The extent of $\mathrm{RPI}-\mathrm{X}$ regulation}

$\mathrm{RPI}-\mathrm{X}$ has become the benchmark style of regulation and is prevalent in both developed and emerging economies. The focus of this paper is on OECD (developed) nations, and we illustrate in Chart 1 which industries have adopted RPI$\mathrm{X}$ in at least a part of each industry. It has been widely applied in particular in energy, telecoms, and airports.

\section{Use of RPI-X regulation in OECD countries}




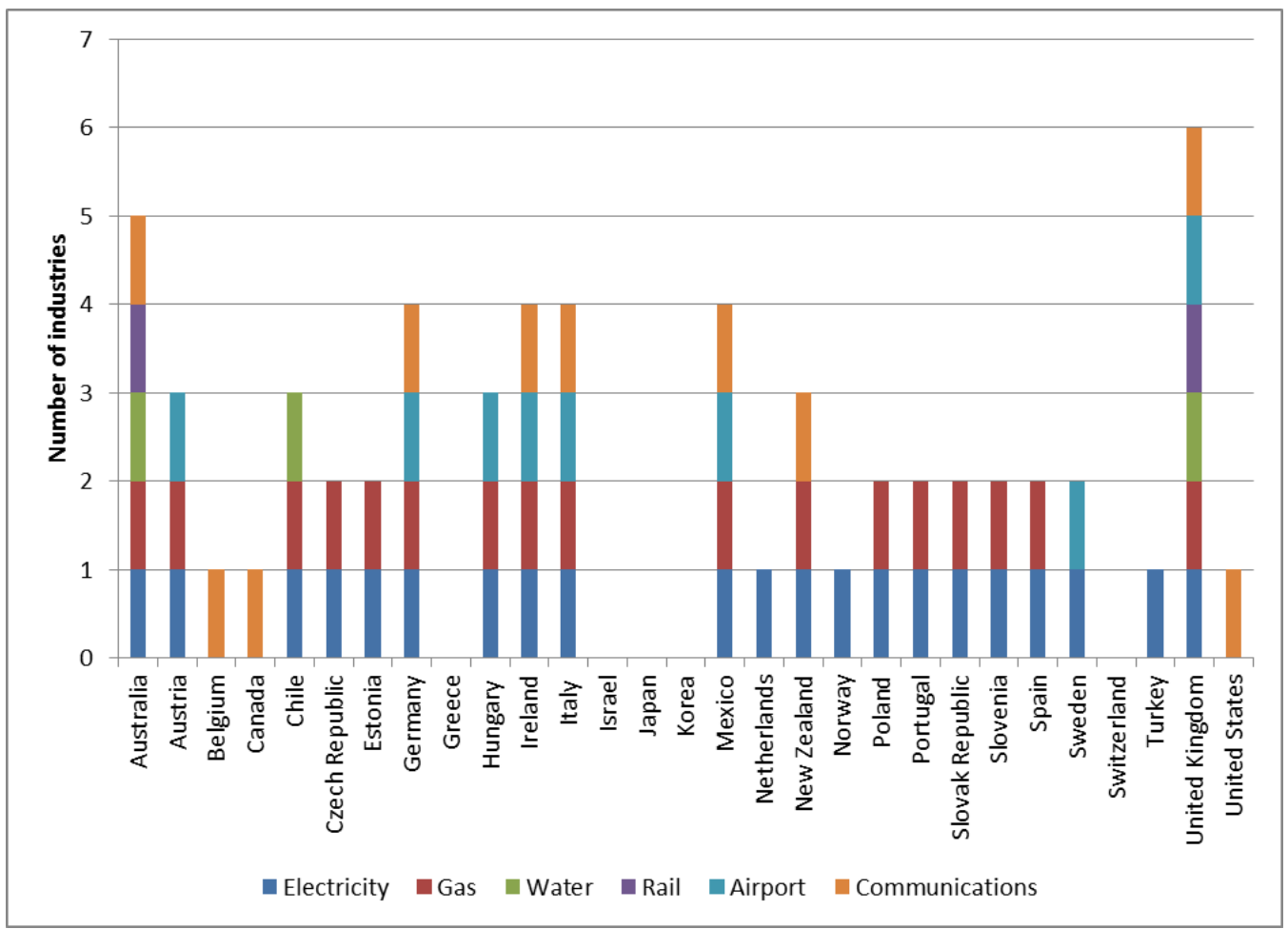

Source: Author, compiled from a wide variety of sources

As can be seen from the chart, nearly all OECD countries have adopted price cap regulation in at least one industry. The approach is most prevalent in electricity, followed by gas, then telecoms, airports, rail and water, and each are discussed in the sections below. It is worth noting, however, that the coverage of price controls within industries covered by the charts varies: the trend has been for regulation increasingly to focus only on the network parts of businesses, but there remain examples where regulation applies to final customer prices or vertically integrated entities.

\section{Energy}

RPI-X regulation has become very common in regulated energy networks, including both energy and gas, and transmission and distribution. Its introduction has typically been associated either with a substantial reform of the industry, for example associated with liberalisation of the wholesale energy markets, or alternatively to provide an acceptable regulatory framework prior to a privatisation.

For example, $\mathrm{RPI}-\mathrm{X}$ regulation was introduced into the Spanish electricity industry in 1997. Prior to this, there was a form of rate of return regulation known as the Stable Legal Framework (El Marco Legal Estable, or MLE). A set of reforms introduced a wholesale electricity market which necessitated the creation of an access pricing regime for networks, and the establishment of price controls for transmission and distribution. All of the major integrated electricity companies at that time were listed on the Madrid Stock Exchange, so this was a major reform of an industry already 
mainly in private ownership. In contrast, in Portugal, price controls were established shortly after as part of the creation of a framework to facilitate the privatisation of the dominant integrated electricity company, EDP.

As can be seen from the chart, there are many other examples both for electricity and gas. Most OECD countries which have adopted RPI-X regulation for electricity have also done so for gas, indeed it is now normal for the same organisation to oversee the regulation of both electricity and gas.

\section{Water}

The approach is less common in water. An exception to this is in Chile, an OECD member since 2010, which is one of the few countries where a sale of water assets over 1988-90. Every five years there is a formal renegotiation process which sets prices for the following five years. The approach is to assess the costs of a "model" (i.e. efficient) company, and final price controls are expressed in terms of cost parameters of that company. Prices are indexed to weighted averages of consumer and producer price inflation. (e.g. see the final determination for Aguas Andinas for the price control effective from 2010-15 in SISS (2010)).

Parts of the water sector in Australia effectively have price cap regulation. Oversight of prices of metropolitan water suppliers is overseen by state-based regulators (see Productivity Commission (2011). The institutional arrangements in each state differ state, but in New South Wales, for example, the Independent Pricing and Regulatory Tribunal (IPART) has been granted powers to set prices for certain government owned water utilities. It sets prices for defined 4 year periods, and the process of review of price determination is very similar to that of the UK water sector (for example see IPART (2012). It should, however, be noted that the operation of other segments of the Australian water sector, with active water entitlement trading, and separate pricing arrangements for bulk water, are in stark contrast to what is observed in the UK which currently regulates the entire water value chain as a vertically integrated activity.

Elsewhere, though, there are alternative ways of controlling prices. This is not because of an absence of private sector participation but rather because the management of water and sewerage is typically the responsibility of local authorities which grant concession contracts of long but limited duration (typically $20-50$ years, with some shorter contracts giving renewal provisions). For example, in France, water supply has been undertaken in the private sector since 1853. Water provision though is delivered through approximately 4,500 contracts, and sewerage through 4,000 . Despite the very large number of individual contracts, and the potential for competition, the market is now dominated by three companies: Veolia, Suez Environnement and Saur. 


\section{Transport}

$\mathrm{RPI}-\mathrm{X}$ regulation is also rarely seen in the rail industry, with the UK being the most notable example of it. RPI-X regulation has been applied in Australia, though, to the infrastructure (or "below rail") operations of Aurizon which operates a freight network in Queensland. The Queensland Competition Authority (QCA) undertakes regular reviews of prices for the bulk of the network. Access charges are regulated, but charges made by the rail operators for "above rail" operations are freely negotiated.

Other methods of regulation have normally been applied to freight rail. In the US, for example, rail companies, which are vertically integrated, are subject to a clever form of ex post regulation. This gives a lot of freedom for rail companies to set prices for shipments where the shipper is deemed to be able to switch between rail companies or other transport modes, with potential restrictions on prices when shippers are deemed to be "captive" to a particular network or form of transport. The aim is for the regulation to be light-handed, to maximise revenues from customers that might switch away from the network, but to provide protection to shippers paying the highest prices in the event that overall revenues for the network are too high. To date, overall revenues in the industry have been insufficient to provide a reasonable return on capital to the whole industry (or "revenue adequacy"). That is now likely to happen within the next few years and the application of the current regulatory framework may therefore change very significantly. A move to a price cap system, however, appears most unlikely.

Forms of price cap regulation are commonly used for control of prices for airports, for example major European hubs such as Frankfurt and Paris. Australia also had a price control mechanism for major airports but has subsequently moved to a system of price monitoring with prices directly negotiated between airlines and airports.

\section{Telecommunications}

Telecoms is the sector where RPI-X regulation started, and as shown in the chart has been used widely. Initially, the price cap was applied to retail tariffs, and in some countries direct restrictions on retail prices still apply. For example, in Australia, the dominant provider Telstra has price control restrictions which were extended to June 2015 (see Australian Government (2014)). The trend, though is for competitive forces to apply to final tariffs, and for price controls, often within an RPI$X$ framework, to apply to the costs of industry segments. This is the approach taken within the UK, and many other countries. Even the US, which has not used price cap controls in utility industries has been using them in telecoms since 1990 (see for example FCC (1999). It is now commonly used to regulated fixed line telecoms networks, including local exchange carriers (including the "last mile") as well as for interstate services. 


\section{Creation of an asset class}

Introduction of RPI-X has been associated with privatisations, and so has facilitated the introduction of private capital into infrastructure sectors. The public to private transfer could have been done without RPI-X, but without it it is unlikely that we would have seen the efficiency gain from introducing private capital, one of the main public policy reasons for privatisation.

Over the same period, there has been a growing investor demand for assets with long duration, low volatility and inflation protection. Pension funds have long dated liabilities which increase with inflation, and the expected cash flows from assets regulated using $\mathrm{RPI}-\mathrm{X}$ are attractive to such investors.

This has led to the establishment of an asset class focused on infrastructure. A range of specialist infrastructure investors have been established to invest directly in infrastructure including Macquarie Group, Industry Funds Management, Brookfield Asset Management, and Alinda Capital partners (see Financial Times (2013)). . Some institutional investors have created their own teams of invest in assets directly. Canadian institutions, for example the specialist investor Borealis (created by the Ontario Municipal Employees Retirement Scheme (OMERS)) have been at the forefront in this trend. In total, Preqin data reports that assets under management of these funds amount to some $\$ 280 \mathrm{bn}$. In addition, investors are able to invest in listed infrastructure, and the total market capitalisation of these is well over $\$ 2$ trillion, depending on the precise definition of infrastructure. Specialist funds have been established to invest in these securities, and the largest of these (by funds under management) is RARE Infrastructure.

Infrastructure is increasingly being treated as an asset class in its own right, and referred to as such by advisory companies (e.g. see Morningstar (2013)). There is also academic research supporting this, for example Blanc-Brude (2013). More tellingly, investors are explicitly making choices about asset allocation into infrastructure. The specialist data provider Preqin (2014) has surveyed current and planned infrastructure allocations by type of institutional investor of which $41 \%$ now have an explicit separate target allocation to infrastructure. Allocations vary by type of institution, but the average is $4.3 \%$ of funds under management, and is targeted to increase to $5.7 \%$.

Of course infrastructure is by no means synonymous with RPI-X regulation: many infrastructure assets have different forms of regulation, have long term contracts or have revenues determined by markets. Many of the assets targeted by infrastructure investors, though, do have $\mathrm{RPI}-\mathrm{X}$ regulation, and these assets are seen as particularly valuable because of the inflation protection, and protection 
against capital loss that owners of these assets typically enjoy. The prevalence of $\mathrm{RPI}-\mathrm{X}$ regulation has been important in facilitating the development of this asset class. Including the protections to investors from the use of regulatory asset values as part of the implementation of RPI-X regulation has contributed to the confidence in regulation, but it should be noted that as in the UK RAV protection is often applied later once initial privatisation has occurred.

\section{Reflecting on international experience}

It is clear from the above discussion that RPI-X has become something of a benchmark approach to regulation. However, as regulatory practitioners know all too well, there is no single approach to the implementation of RPI-X, and in every industry and country there are very significant differences. These differences include:

- Price caps vs revenue caps. With price caps, the asset owner faces volume risk, whereas in revenue caps this is borne by the consumer.

- Whether regulatory asset values underpin the price controls. Initial price controls in the UK were not explicitly underpinned by asset values, an approach which came later. In most examples where RPI-X has been introduced that is now explicitly associated with an explicit asset value. It is not, however, universal, and an example where there is no asset value is distribution regulation in Spain.

- The legal status of regulatory values. In the UK, regulatory asset values are determined by custom and practice, are the mechanism by which regulators fulfil their financing obligations, but have discretion in how they are treated. In many other countries, the regulatory asset value has more legal status, for example being referred to in statute law.

- The nature of the regulatory value. It may be related directly to an accounting value, or a valuation of physical assets. It may be calculated as the value of a model network. A further approach is for it to be simply treated as a liability of customers to be met in current and future controls under a set of rules, the UK approach.

- The type of return used to calculate revenues. These can be pre-tax, post-tax, or "vanilla" (where tax is assumed to be dealt with separately in controls), and may be quoted in real or nominal terms.

- The nature of indexation. Consumer or producer prices can be used, or other measures of inflation (e.g. construction costs). There may be different measures used to index asset values from those used to index prices or revenues. 
- Incentive arrangements across price controls. In long-term businesses, incentive arrangements sometimes need to span price control periods which are typically up to five years (the eight year control now used in UK energy networks is exceptional). Many countries (e.g. France, Italy and Spain) have used incentive arrangements across controls to incentivise particular types of capital spending.

- Whether operating expenditure, capital expenditure are treated separately, or together as total expenditure. The use of "totex" is becoming standard in the UK, for some time it has been part of the approach used in Germany.

- The extent and type of benchmarking used. Standard benchmarking approaches have been applied, some countries have developed more sophisticated approaches (e.g. see Kuosmanen (2012) for the "StoNED" approach used in Finland).

These are mechanical differences, and need to be understood by prospective investors. There are, however, other differences that have a substantial impact on the success or otherwise of a particular regulatory framework, and some of these are discussed below.

\section{Market for corporate control}

One of the main reasons for implementing RPI-X price controls is to incentivise companies to improve efficiency. In order for this to work, though, managers need to have an incentive to respond to those incentives.

Australia provides an example of where the same regulatory framework has been imposed on a range of companies some of which have been privatised while others remain in public ownership (under the control of State rather than Commonwealth government). There is substantial evidence that, controlling for difference in operating conditions, state-owned businesses have increased their capacity and regulatory asset bases inefficiently in contrast to those that have been transferred to private ownership.

All regulated network businesses increased capital expenditure over the period 2002-10, but increases in expenditure by private networks in Australia were on average lower than those for those in state ownership (Productivity Commission (2013), page 241, and Grattan Institute (2012)). These analyses show that there is also a stark difference in the level of operating expenditure equivalent networks when controlled for customer density, and that differences have become progressively worse.

The Australian evidence is relatively clear cut, but there are other examples where it appears that corporate governance associated with partial state ownership has a 
negative impact. For example, the main assets of ADP are the Paris airports which are subject to an RPI-X price control regime. However, charges are lower than permitted by the regulatory framework and return on capital employed below those used to determine price controls. Overall aeronautical revenues at around $€ 18 /$ passenger are higher than those at other European airports (e.g. Frankfurt revenues/passenger are around $€ 14$ /passenger). The evidence is not clear cut, but it does appear that many managerial and commercial decisions are indirectly affected by the ownership structure. This contrasts with Frankfurt airport, which although it also has partial public ownership (by the State of Hesse), its approach is more commercial.

In theory, a well-designed set of incentives can work for publically owned regulated companies. The evidence suggests that ownership matters, and incentives in RPI-X regulated businesses are likely to be more effective when there is an effective market for corporate control.

\section{Appeals mechanisms}

The importance of independence of regulators is well accepted. It is well accepted that UK regulators act largely independently, although there are exceptions. In the UK, regulatory decisions may be made in the knowledge of the political context, but decisions do not need ratification by politicians. This is not the case, for example, in Spain where the regulator is essentially an advisory body with final decisions taken by government. The regulator was formerly the CNE, since October 2013 energy regulation has been performed by a new integrated sector and competition regulator the CNMC. Decisions on price regulation still need to be ratified by the relevant ministry albeit on the basis of a defined methodology (e.g. see Government of Spain (2014)).

Even where regulators have authority, though, the appeal mechanism for their decisions has an important impact on the way decisions are taken. For example, in Australia, in the past utilities could appeal individual elements of a regulatory decision. From 2008-12, there were 19 appeals to the Australian Competition Tribunal, and the bulk were on questions of the appropriate Weighted Average Cost of Capital to be used in determinations. Most were successful. On average, these led to a $8 \%$ increase in utility revenues, or around $\$ 3.2 \mathrm{bn}$. The important feature here was that specific items could be appealed and so there was a cherry picking of issues to consider, rather than a balanced review of a determination as a whole. The mechanism has since been reformed with a tougher threshold for review and this is likely to limit the reviews that take place.

However, the appeal body remains the Australian Competition Tribunal, and it is legitimate to question whether the constituents of this panel will typically have the 
expertise to review decisions. The review body established to assess whether the appeal mechanism should be changed recommended that a new body should be established. This experience is in contrast with the experience in the UK where appeals are decided by panels of Commissioners of the Competition Authority (now the CMA, formerly the $\mathrm{CC}$ ), and are recognised experts in regulatory matters.

This is not a unique example of issues with appeals. Finnish networks are regulated by an independent Energy Market Authority which undertook a review of network pricing in 2011 for the 2012-15 regulatory period (see Energimarknadsverket (2011)). One point of contention for the transmission company Fingrid was the allowed rate of return, which appealed the decision. In Finland appeal is to a court, and the initial appeal was in favour of the regulator. The decision has been further appealed to Finland's Supreme Court and as of July 2014 remains pending.

The advantage of a legal appeal mechanism is that it provides a solid framework within which decisions are taken, which can provide a degree of certainty for investors. If the appeal body lacks expertise, though, it can lead to inappropriate appeals, and influence the decisions made by the regulator prior to appeal.

\section{Rules vs discretion}

A related issue is the extent to which regulators should have discretion. Prior to 2013, the Australian Energy Regulator (AER) estimated WACC with a formulaic approach to determining the parameters. From 2013, the approach as set out in AER (2013) is to draw on a wider range of evidence, within the framework of the Sharpe-Lintner Capital Asset Pricing Model (CAPM).

While one can disagree with elements of the proposed approach (for example the precise method of calculation of the cost of debt, or the approach to using imputation credits), the change to allowing a wider range of evidence into a WACC estimate is welcome. Market evidence on an appropriate WACC should not be limited just to the parameters that can be estimated, as other data such as prices paid for assets do contain information on the returns that investors expect from assets.

The trade-off here is between the certainty offered to investors from a pre-defined framework, and the benefits to investors and customers from allowing regulators to have discretion. Investors do value certainty, and for investment decisions with decade long implications the commitment by regulators to the use of a regulatory asset value mechanism, combined with a sensible approach to determining the WACC will facilitate appropriate investment decisions. But an over-rigid application of rules without allowing for change can ossify a framework, and prevent evolution that can be in the interests of customers and investors. 


\section{Evolution of regulatory frameworks}

A good example of evolution of regulation is shown by Australian airports. Prior to 2002, regulation was through price control regime with the full architecture of regulatory asset values. This was replaced in 2002 by a price monitoring regime. The Australian Competition Authority, the ACCC, is required to publish an annual monitoring report on prices and non-price factors. From time to time the Productivity Commission is instructed to conduct reviews of the performance of the regime (e.g. Productivity Commission (2011)).

Under the current regime, airlines and the airports negotiate charges directly, and have the right of appeal to the ACCC. Progress has not always been smooth. For example, the latest ACCC (2014) report highlights concerns about pricing and the quality trends at Sydney Airport. Nevertheless, neither airlines nor the airport would welcome a return to price cap regulation, and a range of measures point to Sydney being one of the best run airports globally.

Of course for airports the customers, airlines, are a relatively small group, and so direct negotiation is manageable. This may not be possible for energy and water networks. It does, however, indicate that regulation can evolve, and it is possible for evolution to benefit both customers and investors.

\section{Concessions and RPI-X regulation}

Use of regulatory asset values to determine revenues is a core element of many price control frameworks. This is helpful in facilitating investment, as it provides a method for regulators to give commitment to investors that they will receive an appropriate financial return on a long duration asset (see Stern (2013)).

Some companies do not own infrastructure assets into perpetuity, but are granted a concession for a limited period. Concession contracts typically set out prices that can be charged for the duration of the agreement. There are, however, instances where an RPI-X form of regulation is grafted onto an underlying concession agreement. This may lead to a rather important inconsistency: investments made under the RAB framework may in theory have a value; but the concession agreement may have no compensation arrangements at termination. Regulation of French energy networks have this feature.

\section{Implications for infrastructure investment}

There is much discussion around the need for increased capital expenditure on infrastructure. Estimates are for an investment of $\$ 60-70$ trillion globally from now 
until 2030 , or $\$ 3.5-4$ trillion per year. At the upper end this amounts to a little over $4 \%$ of GDP (see for example McKinsey (2013)).

The focus of discussion is very often about the infrastructure "gap", which represents the difference between investment that is seen to be needed and investment that is expected. This leads to a focus on financing, and policy changes to encourage long term financing. For example, at the G20 meeting of finance ministers in Sydney in February 2014, a plan was announced to raise global GDP by $2 \%$, and facilitating investment in infrastructure was one way to achieve this. Another example of this is the report on long term financing by Group of Thirty (2013).

It is not at all clear, though, that availability of financing is a problem. The evidence from financial markets is that there are more funds available than there are projects to invest in, as evidenced by data from Preqin (2014).

A discussion of the regulation of infrastructure projects potentially has a far more prominent role to play. The right forms of regulation can incentivise the private sector to play a growing part in the infrastructure investment needs, and at the same time aim to reduce the investment needs. The aim is not to meet the defined need, but to procure the investment in a way that best meets needs, and hopefully at lower cost. RPI-X, and appropriate developments of it, can play a role in this.

\section{Conclusion}

This discussion has taken us a long way from the Littlechild (1983) report, and has only scratched the surface of the immense contribution that the report has made. $\mathrm{RPI}-\mathrm{X}$ regulation has been implemented in many countries and industries, and transformed the role of the private sector in infrastructure provision.

The outcomes achieved, however, depend on the approach to implementation. In many cases the implementation copies approaches used mechanistically, rather than designing the framework with particular outcomes in mind. The outcomes of the establishment of a price control regime were well understood and explained in the original paper:

"From the point of view of public policy, the primary purpose of regulation is to protect the consumer. The primary purpose should be distinguished from the secondary purposes. Inefficiency and high costs, and the ability to earn excess profits and pay high wages are of significance insofar as they lead to higher prices for the consumer. The consumer's prime concern is with the range and quality of the goods and services he is offered, and the terms on which these goods and services are offered, rather than with the reasons lying behind it all. The means should not be confused with the ends." 
The impact of the RPI-X paper is hard to overstate. But in taking forward application of RPI-X, it should be done intelligently, and in particular the means of regulation should not be confused with the ends, as expressed in the original Littlechild (1983) report. The success of regulation in the UK has been its ability to reinvent itself in response to new challenges (e.g. see Stern (2014)). In other OECD countries, regulation sometimes focuses on the mechanics of what is believed to be a good RPI-X system, and a focus on "ends" would often be beneficial to all stakeholders.

\section{References}

ACCC (2014). Airport Monitoring Report 2012-13.

https://www.accc.gov.au/system/files/Airport\%20Monitoring\%20Report\%20201213 2.pdf

Australian Energy Regulator (2013). Better regulation: rate of return guideline. AER. Available at http://www.aer.gov.au/sites/default/files/AER\%20Rate\%20of\%20return\%20guideline \%20-\%20December\%202013.pdf

Australian Government (2014). Telstra Carrier Charges - Price control arrangements, Notification and Disallowance Determination No 1 of 2005 (Amendment No 1 of 2014). http://www.comlaw.gov.au/Details/F2014L00786

Blanc-Brude, Frederic (2013). Toward Efficiency Benchmarks for Infrastructure Equity Investments. EDHEC-Risk Institute. Available at http://professoral.edhec.com/ medias/fichier/edhec-publication-towards-efficientbenchmarks-f 1361798259166-pdf

Energimarknadsverket (2011). Regulation methods for the assessment of reasonableness in pricing electricity transmission network operations in the third regulatory period starting on 1 January 2012 and ending on 31 December 2015.

FCC (1999). Fifth report and order and further notice of proposed rulemaking. FCC 99-206.

Financial Times (2013). Infrastructure: asset class gains more appeal. July 72013 , London: Financial Times. 
Finlex (2012). Decision under appeal J497/11/E1. Available at www.finlex.fi.

Government of Spain (2014). Royal Decree 8/2014. Medidas urgentes para el crecimiento la competitividad y la eficincia. BOE (Boletín Oficial del Estado), available at www.boe.es.

Group of Thirty (2013). Long term finance and economic growth. Available at http://www.group30.org/images/PDF/Long-term_Finance_hi-res.pdf

IPART (2012). Review of prices for Sydney Water Corporation's water, sewerage, stormwater drainage and other services. Final report, June 2012. IPART. http://www.ipart.nsw.gov.au/Home/Industries/Water/Reviews/Metro Pricing/Review of prices for Sydney Water Corporations water sewerage stormwater and othe r services prices from 1 July 2012/19 Jun 2012 - Final Report/Final Report Review of prices for Sydney Water Corporations water sewerage stormwater drainage and other services from 1 July 2012 to 30 June 2016

Kuosmanen, Timo (2012). Stochastic semi-nonparametric frontier estimation of electricity distribution networks: application of the StoNED method in the Finnish regulatory model. Energy Economics 34 (2012) 2189-2199.

https://noppa.aalto.fi/noppa/kurssi/30e09000/materiaali/30E09000 electricity distrib ution regulation.pdf

Littlechild, Stephen C. (1983). Regulation of British Telecommunications' profitability. Report to The Secretary of State. February 1983. London: Department of Industry.

Littlechild, Stephen C. (2014). RPI-X, competition as a rivalrous discovery process, and customer engagement. Paper presented at the Conference The British Utility Regulation Model: Beyond Competition and Incentive Regulation? LSE 31 March 2014.

McKinsey (2013). Infrastructure productivity: how to save $\$ 1$ trillion a year. McKinsey Global Institute. Available at:

http://www.mckinsey.com/insights/engineering_construction/infrastructure_productivi ty

Morningstar (2013). Infrastructure should be own asset class.

http://www.morningstar.com.au/funds/article/own-asset-class/5942

Preqin (2014). Infrastructure Spotlight, June 2014. www.preqin.com. 
Productivity Commission (2011). Australia's Urban Water Sector. Producitivity Commission Inquiry Report. Productivity Commission. http://pc.gov.au/ data/assets/pdf file/0017/113192/urban-water-volume1.pdf

SISS (2010). Fija formulas tarifarias de los servicios de produccion y distribution de agua potable y recoleccion y disposicion de aguas servida para la empresa Aguas Andinas S.A. Santiago, Chile: SISS. Available at http://www.siss.gob.cl/577/articles$\underline{6991 \mathrm{dt} 01 . \mathrm{pdf}}$

Stern, Jon (2013). The role of the regulatory asset base as an instrument of regulatory commitment. CCRP working paper No 22.

Stern, Jon (2014). The British utility regulation model: its recent history and future prospects. Utilities Policy, forthcoming.

Wood, Tony (2012). Putting the customer back in front: how to make electricity cheaper. Grattan Institute.

http://grattan.edu.au/static/files/assets/7a8390e0/178 energy putting the customer back in front.pdf 